\title{
Extended endoscopic endonasal approach for resection of tuberculum sellae meningioma
}

\author{
Gabriel Zada, MD, MS, ${ }^{1}$ Vance L. Fredrickson, MD, ${ }^{1}$ and Bozena B. Wrobel, MD ${ }^{2}$ \\ 'Departments of Neurological Surgery and ${ }^{2} \mathrm{Head}$ and Neck Surgery, Keck School of Medicine, University of Southern California, \\ Los Angeles, California \\ Meningiomas are the most prevalent primary intracranial tumor, with 3\%-10\% arising from the tuberculum sellae. Opti- \\ mal management consists of total microsurgical resection with preservation of surrounding structures. The authors pres- \\ ent a 64-year-old woman with progressive bilateral vision loss, including visual acuity deficits and bitemporal hemianop- \\ sia. MRI revealed a 2-cm tuberculum sellae meningioma causing optic apparatus compression. An extended endoscopic \\ endonasal transtuberculum approach was utilized for gross-total resection, including microdissection of tumor from the \\ optic chiasm and infundibulum. Closure was performed with multilayer tensor fascia lata autograft and a pedicled nasal- \\ septal flap. The patient's postoperative exam showed visual improvement and normal pituitary function.
}

The video can be found here: $h$ ttps://youtu.be/ZfNB_rhlyel.

KEYWORDS endoscopic; neuroendoscopy; transsphenoidal; transtuberculum; meningioma

SUBMITTED July 12, 2017. ACCEPTED August 7, 2017.

INCLUDE WHEN CITING Published online October 1, 2017; DOI: http://thejns.org/doi/abs/10.3171/2017.10.FocusVid.17285.

CORRESPONDENCE Gabriel Zada, Department of Neurological Surgery, Keck School of Medicine, University of Southern California, 1200 North State Street, Ste. 3300 Los Angeles, CA 90033. email: gzada@usc.edu. 